\title{
DESCOBRINDO O MUNDO POR MEIO DO BRINCAR HEURÍSTICO E DO BRINCAR TELÚRICO
}

\section{DISCOVERING THE WORLD THROUGH THE HEURISTIC PLAYING IT'S FROM TELLURIC PLAYING}

\section{DESCUBRIR EL MUNDO POR MEDIO DEL BRINCAR HEURÍSTICO Y DEL BRINCAR TELÚRICO}

\author{
Salete Rosemara Gazola \\ Graduação em Pedagogia \\ Faculdades Integradas de Jaú \\ E-mail: salete_gazola@live.com
}

Suselaine A. Zaniolo Mascioli

Pós-Doutora em Educação - sub-área: Educação Infantil - UFSCAr. Pesquisadora Integrante do "Núcleo de Estudos e Pesquisas sobre a Escola de Vigostky" - Neevy - UFSCar e do GEERERI Grupo de Estudos "Educação e Relações Étnico-Raciais na Temática Indígena”. Docente: FIJ- Faculdades Integradas de Jáu; UNIP -Universidade Paulista.

E-mail: suse.zaniolo@gmail.com

\section{RESUMO}

Tendo em vista que o brincar na Educação Infantil é imprescindível para o desenvolvimento de habilidades infantis desde a mais tenra idade, este estudo tem como tema o brincar Heurístico por meio do brincar do Telúrico, pois são duas vertentes que devem estar presentes no cotidiano dessa modalidade de ensino. A primeira está intimamente ligado ao brincar pelas descobertas, livre e espontâneo, enquanto a segunda diz respeito ao brincar de construir brinquedos por meio dos elementos da natureza. Assim, a Teoria Histórico-Cultural pode auxiliar tais brincadeiras quando a mediação é feita pelo professor para o processo de ensino/aprendizagem, a fim de analisar as possibilidades e contribuições do brincar Heurístico com elementos advindos da natureza para o desenvolvimento de habilidades infantis. A partir desse pressuposto, o objetivo geral deste trabalho é discutir os benefícios da utilização dos elementos naturais para o brincar. Realiza-se, então, uma pesquisa qualitativa de cunho bibliográfico, elaborada a partir de livros, artigos científicos, dissertações, teses e fontes paralelas: internet, revistas e jornais, bem como pesquisa documental com análises de documentos legais que embasam a Educação Infantil, a infância e o brincar.

Palavras-chave: Educação Infantil. Brincar Heurístico. Brincar Telúrico.

\section{ABSTRACT}

Considering that playing for Child Education is essential for the development of children's skills from an early age, this study theme on the Heuristic playing through the Telluric playing, because they are two aspects that must be present in the daily life of this kind of teaching; the first is closely linked to playing by the discoveries, free and spontaneous ways, white the second

$$
\text { RELEDUC | ISE | v. } 2 \text { | n. } 1 \text { | fev. } 2019
$$


concerns by playing toys with toys by the elements of nature. In this way, the HistoricalCultural Theory can help such games when mediation is done by the teacher for the teaching / learning process, in order to analyze the possibilities and contributions of the Heuristic playing with elements from nature for the development of children's abilities. From this assumption, the general objective of this work is to discuss the benefits of using natural elements to play with. A qualitative bibliographic research is carried out, based on books, scientific articles, dissertations and theses and parallel sources, such as the internet, magazines and newspapers, as well as documental research with studies of legal documents that support the Child Education, childhood and play.

Keywords: Child Education. Play Heuristic. Play Telluric.

\section{RESUMEN}

En el caso de la educación infantil, es imprescindible para el desarrollo de habilidades infantiles desde la más tierna edad, este estudio tiene como tema el jugar Heurístico por medio del juego del Telúrico, pues son dos vertientes que deben estar presentes en el cotidiano de esa modalidad de enseñanza; el primero está íntimamente ligado al jugar por los descubrimientos, libre y espontáneo, mientras que el segundo se refiere al juego de construir juguetes por medio de los elementos de la naturaleza. Así, la Teoría Histórico-Cultural puede auxiliar tales bromas cuando la mediación es hecha por el profesor para el proceso de enseñanza / aprendizaje, a fin de analizar las posibilidades y contribuciones del jugar Heurístico con elementos provenientes de la naturaleza para el desarrollo de habilidades infantiles. A partir de ese presupuesto, el objetivo general de este trabajo es discutir los beneficios de la utilización de los elementos naturales para el juego. Se realiza una investigación cualitativa de cuño bibliográfico, elaborada a partir de libros, artículos científicos, disertaciones, tesis y fuentes paralelas: internet, revistas y periódicos, así como investigación documental con análisis de documentos legales que fundamentan la Educación Infantil, la infancia y el juego.

Palabras clave: Educación Infantil. Jugar Heurístico. Jugar a Telúrico.

\section{INTRODUÇÃO}

É perceptível ao estudar a história da humanidade que desde os tempos mais remotos, a criança sempre fora tratada pelos adultos como seres inaptos, "[...] uma vez que, etimologicamente, o próprio termo, oriundo do latim, significa a incapacidade de falar." (MASCIOLI, 2012, p. 8).

Conforme Piorski (2016) o percurso das crianças ao longo dos séculos fora marcado pela exploração e esquecimento, pelo abandono exacerbado da infância em muitos contextos sociais, com a visão vertical dos adultos em diversas culturas, as quais não acreditavam na importância do brincar para o desenvolvimento infantil. A criança, era vista como um indivíduo originário do desconhecido, que passou por incontáveis sofrimentos e que em muitos casos acabaram indo a óbito dentro do grupo e na sociedade em que habitavam:

$$
\text { RELEDUC | ISE | v. } 2 \text { | n. } 1 \text { | fev. } 2019
$$


[...] as crianças, como as aquilombadas, crianças escravas, as vítimas de epidemias, e de genocídios, as que passam por disciplinas severas [...] condenadas ao trabalho nas fábricas, extirpadas em sua sexualidade, abandonadas ao entretenimento e consumo [...] (PIORSKI, 2016, p. 38).

Assim, a criança fora negligenciada mesmo quando vista como progenitora da espécie, que deveria ser educada para o desenvolvimento político, religioso, econômico, e/ou para o consumo. Tal abandono da infância, mesmo na modernidade, ainda acontece, pois o Estado, suas concepções e políticas, através da escolarização visam “[...] doutrinar, incutir ideologias, plantar um padrão civilizacional baseado no desenvolvimento econômico e no acúmulo de bens e informação." (PIORSKI, 2016, p. 40). E, neste sentido, preconiza que:

O mundo, a cultura local, o real, é o lugar que a criança se goteja, se derrama ou se faz tempestiva, e, na pior e bem comum das hipóteses, resseca. [...] Quando a criança encontra espelhos no mundo, na cultura [...] ela se aproxima de seu eu e de suas fontes criadoras [...]. (PIORSKI, 2016, p. 30).

Este estudo terá como base a Teoria Histórico-Cultural que tem o psicólogo russo Vygotsky $^{1}$ como mais valoroso representante com seus estudos sobre o desenvolvimento infantil, assim como outros psicólogos russos, que igualmente contribuíram para o aprimoramento e divulgação do assunto, como Leontiev, Luria e Elkonin. A criança, para essa Teoria, deve ser considerada como um ser singular, único, indivisível, ativo, completo, que tem vontades próprias, desejos e necessita de cuidados a fim de que se desenvolva plenamente. Porém:

Muitas vezes vista apenas como um ser que ainda não é adulto, ou é um adulto em miniatura, a criança é um ser humano único, completo e, ao mesmo tempo, em crescimento e em desenvolvimento. É um ser humano completo porque tem características necessárias para ser considerado como tal: constituição física, formas de agir, pensar e sentir. É um ser em crescimento porque seu corpo está continuamente aumentando em peso e altura. É um ser em desenvolvimento porque essas características estão em permanente transformação. As mudanças que vão acontecendo são qualitativas e quantitativas - o recém-nascido é diferente do bebê que engatinha, que é diferente daquele que já anda, já fala, já tirou as fraldas. O crescimento e o

\footnotetext{
1 "A grafia do nome do autor é encontrada na literatura de formas distintas, dependendo do idioma de origem das traduções e das obras utilizadas.” (MASCIOLI, 2012, p 17). Neste trabalho optou-se por conservar as grafias correspondentes às obras consultadas.

$$
\text { RELEDUC | ISE | v. } 2 \text { | n. } 1 \text { | fev. } 2019
$$
}


desenvolvimento da criança pequena ocorrem tanto no plano físico quanto no psicológico, pois um depende do outro. (BRASIL, 2006, p. 14).

Dessa forma, o objetivo deste trabalho foi de analisar as contribuições e vicissitudes do brincar Heurístico por meio de elementos provenientes do meio natural para o desenvolvimento mais efetivo de habilidades, valores e comportamentos infantis, assim como discutir sobre a importância da utilização de objetos naturais para o brincar, e discorrer sobre o papel do pedagogo como o mediador entre criança/natureza no espaços de ensino/aprendizagem.

A criança não pode ser vista como uma tábula rasa, que deve ser preenchida por conhecimentos dos adultos, mas que descubra sua capacidade de aprender e modificar o espaço em que habita. Porém está inculcada no ideário das pessoas a visão de que o adulto e a criança se diferenciam apenas no quesito quantitativo, ou seja:

[...] não precisamos mais do que encolher o adulto, torná-lo mais fraco, diminuir suas habilidades e fazê-lo um pouco menos inteligente e teremos uma criança. [...] poucas pessoas que consideram a idéia de que a criança nem sempre é simplesmente uma réplica em miniatura do adulto e que, sob muitos aspectos, a criança difere radicalmente do adulto - que a criança é uma criatura singular, completamente diferente. (VYGOTSKY; LURIA, 1996, p. 152).

Segundo Souza (2007) a educação de crianças pequenas no Brasil, surgiu no final do século XIX e de forma institucionalizada, principalmente, para crianças menos favorecidas. No período de 1930-1970 com a chegada da indústria ao país, pensava-se primeiramente na mãode-obra, e que esta fosse de baixo custo, por isso, as mulheres passaram a trabalhar, uma vez que precisavam complementar a renda familiar.

As crianças do século XXI, desde seu nascimento, já presenciam o globalização e a individualização, em que a competitividade do mercado de trabalho faz com que as escolas os submetam ao início do processo de alfabetização e de conteúdos metodológicos desde a Educação Infantil, para crianças de 0 a 5 anos de idade, sendo esta a primeira etapa da educação básica que compreende as creches e pré-escolas. Essa prática, segundo estudos, pode acabar prejudicando o desenvolvimento da imaginação e criatividade, de relações interpessoais com seus pares, de senso crítico e autonomia da criança. Formas contemporâneas " [...] culturais de comportamento substituem gradativamente as formas primitivas da infância. Desenvolvem-se novas habilidades, novas formas de pensamento, lógica e novas atitudes em relação ao mundo [...]” (VYGOTSKY; LURIA, 1996, p. 177).

$$
\text { RELEDUC | ISE | v. } 2 \text { | n. } 1 \text { | fev. } 2019
$$


Atualmente, o que se espera é que a criança não seja tratada como um adulto em miniatura, mas como um ser social, visto que ela "não é uma abstração, mas um ser produtor e produto da história e da cultura” (FARIA, 1999 apud BRASIL, 2006, p. 13), dessa forma é preciso considerar que a infância é um momento singular, de desenvolvimento integral do eu.

Foi a partir da Constituição Federal de 1988 que a luta pela democratização da escola pública, por meio de movimentos feministas e sociais pelo reconhecimento de creches e préescolas como direito da criança e não apenas das mães trabalhadoras, como também é neste mesmo documento que determina o dever do Estado com os sistemas de ensino, em que as crianças são, de fato, cidadãos de direitos, como definido em seu Art. 227 (Redação dada pela EC n. 65/2010):

É dever da família, da sociedade e do Estado assegurar à criança, ao adolescente e ao jovem, com absoluta prioridade, o direito à vida, à saúde, à alimentação, à educação, ao lazer, à profissionalização, à cultura, à dignidade, ao respeito, à liberdade e à convivência familiar e comunitária, além de colocá-los a salvo de toda forma de negligência, discriminação, exploração, violência, crueldade e opressão. (BRASIL, 1988, p. 172).

No Brasil o Estatuto da Criança e do Adolescente (ECA) em seu Art. 2o da Lei 8069 explicita que "considera-se criança, para os efeitos desta Lei, a pessoa até doze anos de idade incompletos, e adolescente aquela entre doze e dezoito anos de idade." (BRASIL, 1990, p. 7).

Em 1996 foi aprovada a Nova Lei de Diretrizes e Bases da Educação Nacional (LDB, 9394/96), a qual teve sua elaboração iniciada a partir da Constituição Federal de 1988, e que está em vigor até os dias atuais. A Educação Infantil foi definida como a primeira etapa da Educação Básica, antecedendo as outras duas etapas, o Ensino Fundamental e Ensino Médio. Houve a consolidação do atendimento educacional das crianças na faixa etária de 0 (zero) a 6 (seis) anos de idade, com a função de complementar a ação da família e da comunidade, e que em seu Título II - Dos Princípios e Fins da Educação Nacional - Art. $2^{\circ}$ afirma que:

A educação, dever do Estado, inspirada nos princípios de liberdade e nos ideais de solidariedade humana, tem por finalidade o pleno desenvolvimento do educando, seu preparo para o exercício da cidadania e sua qualificação para o trabalho. (BRASIL, 1996, p. 1).

Assim, acredita-se que o brincar está em todos os espaços em que as crianças estão inseridas, no entanto se este não estiver presente, a probabilidade de se ter um ambiente 
improdutivo, infértil e árido é grande, pode se pensar até em um espaço sem expressividade e inanimado, sem alegria e imaginação, sem motivação intrínseca:

Fazendo uma pesquisa sobre a etimologia da palavra brincar, encontrei algo surpreendente: ela é única, não é derivada de nenhuma raiz. Achei isso significativo, pois o brincar é algo sui generis, tão essencial para os seres vivos que não necessita ser derivado de nada. O brincar "é"! (CRAEMER, 2015, p. 47, grifo do autor).

Na concepção de Goldschmied e Jackson (2006) o brincar Heurístico é uma modalidade importante do brincar, utilizado nas creches e pré-escolas. A criança sente-se mais motivada ao descobrir novos objetos, texturas, sons e sabores, principalmente aqueles advindos da natureza e, desse modo, possivelmente irão se interessar mais pela aprendizagem, tornando as aulas mais prazerosas e ricas. Partindo desse pressuposto, a etimologia da palavra Heurístico vem de eurisko, que é derivada de eureca em grego, quando traduzido significa "encontrei”. Heurístico, portanto, é um vocábulo que "serve para descobrir ou alcançar a compreensão de algo" (p. 148).

De acordo com Piorski (2016) o brincar Telúrico está intimamente ligado aos elementos da natureza, a imaginação da criança se torna materialidade quando constrói seu próprio brinquedo. Terra, água, fogo e ar, os quatro elementos da natureza, estão para as crianças ligadas a tudo que existe na Terra, pois "[...] a imaginação telúrica é iniciática na vida do brincar. Os brinquedos do chão fincam a criança no mundo e também a acordam para firmar o mundo em si. [...]” (p. 20). Este elemento faz sucitar reflexões sobre as origens de tudo que existe, das grandezas e acontecimentos, dos mistérios do nascimento e de morte.

\section{DESENVOLVIMENTO}

\subsection{O brincar, o brincar Heurístico e o brincar Telúrico}

$\mathrm{Na}$ atualidade, o brincar, principalmente nas regiões urbanas, tem sofrido grande influência pela crescente violência e progresso, do uso indiscriminado de novos recursos tecnológicos que estão disponíveis aos pequenos, porém:

[...] Apesar da tentação do tablet, dos jogos eletrônicos, do celular, das redes sociais, as crianças - que bom! - continuam brincando. Pode estar mais difícil, talvez, achar um ambiente propício para a brincadeira, mas essa

$$
\text { RELEDUC | ISE | v. } 2 \text { | n. } 1 \text { | fev. } 2019
$$


necessidade intrínseca da criança consegue resistir à sedução hipnotizante dos meios eletrônicos. [...] (CRAEMER, 2015, p. 48).

Para a Teoria Histórico-Cultural o Jogo de Papéis Sociais ou Jogo Protagonizado é extremamente importante nesta fase singular de desenvolvimento, que é a infância. Por isso, Elkonin teve seu foco de pesquisa voltado para o Jogo de Faz de Conta, que é uma brincadeira própria da idade pré-escolar e "[...] nasce das condições de vida da criança em sociedade [...]" (ELKONIN, 1998, p. 36), o seu surgimento está inteiramente ligado com a divisão social do trabalho.

\begin{abstract}
Assim, a base do jogo protagonizado em forma evoluída não é o objeto, nem o seu uso, nem a mudança de objeto que o homem possa fazer, mas as relações que as pessoas estabelecem mediante as suas ações com os objetos; não é a relação homem-objeto, mas a relação homem-homem. E como a reconstituição e, por essa razão, a assimilação dessas relações transcorrem mediante o papel de adulto assumido pela criança, são precisamente o papel e as relações organicamente ligadas a ele que constituem a unidade do jogo. (ELKONIN, 1998, p. 34, grifo do autor).
\end{abstract}

Neste sentido, a concepção de jogo como manifestação equilibrada da imaginação, deu lugar ao jogo por meio da imaginação, em que a criança tem a possibilidade de se afastar da própria realidade, adentrando em uma dimensão particular e fechada "[...] da ilusão autística infantil relacionado com suas inclinações profundas". (ELKONIN, 1998, p. 23). Enquanto jogam as crianças interpretam papéis, que podem ser o esboço das particularidades da fantasia infantil, e que se manifesta através do jogo.

De acordo com Moreira (2006) a Teoria Histórico-Cultural considera que a criança nesta fase pré-escolar desenha, pinta, modela, recorta etc.; mas o jogo está como atividade principal da criança, contudo entende-se por principal, pois é por meio dela que “[...] se desenvolve a origem de mudanças qualitativas da psique infantil, isto é, mudanças que elevam para o pensamento abstrato [...].” (p. 110-1), e dessa forma influenciará ideias, imaginação e linguagem.

[...] Quando brincam de fazer criaturas de barro ou bonecas, de construir casinhas, assumir papéis e destituir-se deles, quando fazem jornadas e longas viagens com seus bonecos heróis, batalhas de vida e morte nas lutas de espada ou de polícia e ladrão, as crianças assumem, na sua gestualidade, nos sons de suas vozes, no pensar e no imaginar, a estrutura simbólica, a semântica épica, a dimensão mágica das antigas lendas e mitologias [...] (PIORSKI, 2016, p. 27).

$$
\text { RELEDUC | ISE | v. } 2 \text { | n. } 1 \text { | fev. } 2019
$$


Para Goldschmied e Jackson (2006) o brincar Heurístico é uma atividade exploratória espontânea, que quando combinada com a curiosidade vívida e a coordenação olho-mão-objeto, vai se tornando cada vez mais precisa. Todo o corpo deve ser envolvido nas descobertas, o brincar necessita de uma ligação íntima com a curiosidade e a exploração de objetos cotidianos. Neste sentido, defendem a importância do método Heurístico para crianças entre 0 a 3 anos de idade que frequentam creches e pré-escolas. O cuidado com os bebês, na maior parte do tempo, está voltado para a alimentação e higiene, porém é de extrema importância para o desenvolvimento das crianças " [...] achar e reservar tempo para o brincar recíproco que ocorre durante essas atividades, e que é um elemento muito vital na vida do bebê quando ele está acordado.” (p. 113). Portanto, o brincar Heurístico:

[...] envolve oferecer a um grupo de crianças, por um determinado período e em um ambiente controlado, uma grande quantidade de tipos diferentes de objetos e receptáculos, com os quais elas brincam livremente e sem intervenção de adultos. (GOLDSCHMIED; JACKSON, 2006, p. 147-8).

O Cesto de Tesouros, foi inventado por Goldschmied em 1987, em contraposição à brinquedos sem relevância e insuficientes para satisfazer as necessidades dos bebês na faixa etária em que estes não conseguem andar sozinhos e permanecem a maior parte do tempo sentados, tal fator pode ser frustrante, o acaba por deixá-los irritados.

Conforme Meirelles (2016) os brinquedos estruturados, ou seja, os brinquedos comprados, não proporcionam a mesma qualidade de aprendizagem do que os objetos não estruturados, estes instigam a imaginação, a autonomia e liberdade de pensar no que fazer com eles e assim criar novas possibilidades, o que mantém durante a livre exploração seu interesse, acompanhando a etapa de evolução da criança:

Nas comparações vivenciadas enquanto manuseiam os objetos não estruturados, as crianças se deparam com a oportunidade de, aos poucos, perceberem o que conseguem ou não carregar, descobrem noções de leve, pesado, grande, pequeno, cheio, vazio, enfim, tudo em situação de brincadeira, tirando o lúdico dos objetos. (MEIRELLES, 2016, p. 21).

Com base na concepção de Majem (2010) o Cesto é uma brincadeira direcionada às crianças entre 6 a 10-12 meses de idade, é uma atividade exploratória em que os objetos devem ser colocados "[...] dentro de uma cesta firme de uns 35 centímetros de diâmetro e uns 8 RELEDUC | ISE | v. 2 | n. 1 | fev. 2019 
centímetros de altura. É importante que a cesta seja sólida, plana, estável e que não tenha alças. A criança deverá poder apoiar-se nela comodamente sem que ela tombe.” (p. 15). Um número bom de objetos seria em torno de sessenta em cada cesto, sendo recomendado que ao seu redor sejam colocadas em média três crianças, sentadas, confortavelmente, para a atividade de exploração. $\mathrm{O}$ aprendizado nesta fase de desenvolvimento em que o cérebro está crescendo rapidamente precisa ser estimulado e o cesto é uma maneira pela qual o brincar dos bebês respondem:

[...] a fluxos de informações advindas das cercanias, pelos sentidos do tato, olfato, paladar, audição, visão e movimento corporal. O Cesto de Tesouros reúne e oferece um foco para uma rica variedade de objetos cotidianos, escolhidos para oferecer estímulos a esses diferentes sentidos [...]. (GOLDSCHMIED; JACKSON, 2006, p. 114).

Em conformidade com Goldschmied e Jackson (2006) os objetos que devem estar no Cesto de Tesouros são aqueles presentes no cotidiano, sendo estes previamente selecionados por adultos responsáveis, uma vez que o Cesto deve estar sempre em permanente mutação e desenvolvimento, por isso os objetos necessitam serem constantemente trocados. Tal princípio pode ser considerado o mais importante no trabalho com o Cesto de Tesouro, pois os bebês precisam estar sempre motivados para as novas descobertas. Os objetos também precisam ser higienizados, cuidados e selecionados pelos responsáveis, estes devem estar atentos à manutenção, troca e se os itens escolhidos não oferecem risco aos bebês.

Para Goldschmied e Jackson (2006) os brinquedos heurísticos necessitam ser trocados constantemente a fim de que as crianças não se sintam desinteressadas e desestimuladas, diferenciando-se daqueles brinquedos que são comprados em lojas especializadas, visto que estes perduram apenas até que a criança enjoe deles, e assim os abandonem e/ou quebrem para ver o que há dentro, posto que estes, normalmente, atendem a faixas etárias de desenvolvimento específicas.

Alguns materiais naturais que podem ser escolhidos pelos adultos, para serem colocados no Cesto de Tesouros são:

Objetos naturais: Abóboras secas; Castanhas grandes; Conchas; Cones de pinho, de diferentes tamanhos; Nozes grandes [...] Um limão; Uma maçã. Objetos feitos de materiais naturais: Alças de sacolas feitas de bambu; Anel de osso; Bola de fios de lã; Calçadeira de osso [...] Objetos de madeira: Apito de bambu; Aro de cortina; Aro para guardanapos; Caixinha forrada de veludo; 
Castanholas [...] Objetos de metal: Apito de escoteiros; Aros de chaveiros entrelaçados; Aros de cortina de metal; Bijuterias; Campainha de bicicleta; Clips de papel; Coador de chá [...] Objetos feitos de couro, têxteis, borracha e pele: Aros para cãezinhos; Bola de borracha; Bola de golfe; Bola de pele [...] (GOLDSCHMIED; JACKSON, 2006, p. 125 - 7).

Goldschmied e Jackson (2006) afirmam que neste contexto, objetos de plástico e/ou brinquedos adquiridos em lojas não são satisfatórios, visto que as crianças manifestam interesse, por descobrirem o que podem fazer com os objetos, sempre "“[...] olhando, tocando, apanhando-os, colocando-os na boca, lambendo-os, balançando-os batendo com eles no chão, juntando-os, deixando-os cair, selecionando e descartando o que o atrai ou não. [...]” (p. 115).

Com base na concepção de Piorski (2016) a imaginação da criança se torna materialidade quando constrói seu próprio brinquedo. Terra, água, fogo e ar, os quatro elementos da natureza, estão para as crianças ligadas a tudo que existe na Terra, das grandezas e acontecimentos, dos mistérios do nascimento e de morte que dão origem à "[...] uma imaginação que estabelece vínculo entre a criança e a natureza e tem capacidades específicas e maior plasticidade: é transformadora, regeneradora." (p. 19).

De acordo com Piorski (2016) a riqueza de materiais que o elemento terra possui para o brincar é extremamente importante, sendo este o elemento que introduz a imaginação da criança nos outros três elementos. Ao construir brinquedos da terra a criança faz uso de seu imaginar, o que lhe permite adentrar “[...] em suas raízes simbólicas, ancestrais, familiares, comunitárias e telúricas (natureza)”. (p. 27). O elemento terra introduz a criança no mundo, na vida em sociedade, conjuntamente com sua subjetividade. O brincar livre com os elementos telúricos podem revelar a alma da criança e independente da cultura em que ela está inserida, a maior influência do imaginar infantil são os elementos da natureza, por isso estes se tornam uma fonte de potencial criador “[...] a imaginação telúrica é iniciática na vida do brincar. Os brinquedos do chão fincam a criança no mundo e também a acordam para firmar o mundo em si. [...]" (p. 20).

Piorski (2016) explicita que ao descobrirem os materiais e construírem os brinquedos, as crianças nem sempre os utilizam em seu sentido denotativo, mas os imaginam. Nos primeiros anos de vida os pequenos não se importam com aparência do brinquedo, os objetos são formulados e reformulados em suas mentes, o que ela deseja é o processo, não o fim em si, ou seja, a aparência do brinquedo que ela constrói pode não ser a mais perfeita aos olhos dos adultos, mas o decurso foi mais prazeroso do que o resultado final, ou seja, "a criança não se

$$
\text { RELEDUC | ISE | v. } 2 \text { | n. } 1 \text { | fev. } 2019
$$


impressiona com a superficialidade formal. Há sempre, de sua parte, um interesse maior pela substância e menor pelo resultado. [...]”' (p. 68).

Segundo Piorski (2016) quando a criança começa a "buscar na natureza materiais pesados ou leves, flexíveis ou longilíneos, modeláveis ou duros, já requer um olhar apurado. [...]” (p. 68), visto que a construção dos brinquedos, a noção e manipulação dos objetos aumenta seu conhecimento de mundo. A criança quer experimentar novas sensações táteis, gustativas, olfativas, auditivas e visuais.

Na concepção de Piorski (2016) os brinquedos telúricos estão para as crianças ligados às descobertas de novas texturas, aromas, sabores, sons e objetos que só a natureza pode lhes proporcionar, há uma ligação entre a criança e estes elementos, tal vínculo pode ser despertado por meio das brincadeiras. A cultura em que os pequenos estão inseridos influenciará de maneira crucial no desenvolvimento destes e "[...] aos poucos, tanto o mundo se torna mais dado à exploração, quanto o corpo se sente mais preparado para investigar. [...]” (p. 95).

A fauna e a flora são importantes nas brincadeiras e descobertas. A fauna desencadeia o desejo de investigar a anatomia dos bichos e é um quesito que deixa as crianças curiosas, principalmente para saber o que há dentro deles. Semelhante com o que ocorre com os objetos. Por isso quando uma criança ganha um brinquedo e em alguns dias o desmonta, ela sente a necessidade de saber o que há no interior. A flora com suas exuberantes e encantadoras flores, frutos, folhas, galhos e etc. remete a beleza que essas espécies proporcionam, deixando as brincadeiras mais belas e perfumadas. Com os elementos da flora produzem-se inúmeros brinquedos. Há os que referenciam aos animais com o sentido de movimento "[...] tantos animais são recriados dos frutos, das sementes e das flores. [...]” (PIORSKI, 2016, p. 73) e há aqueles que produzem sons.

À medida que ocorre o avanço da criança nas etapas da escolaridade que se seguem durante sua vida, os espaços/tempo para o brincar vão sendo diminuídos. Aumentando o tempo de aulas que privilegiam os conteúdos sistemáticos e metodológicos com o propósito de que se tornem adultos bem preparados do ponto de vista capitalista. Atualmente o que se percebe é que os padrões e ideologias que as sociedades tem imposto através da escolarização, desestimulam o caráter criador e recriador da criança, moldando-os.

Conforme exposto, para a Teoria Histórico-Cultural é da cultura que emana a principal influência da criança pequena e sua maneira de brincar. Por conseguinte foram anteriormente citados duas modalidades do brincar. O brincar Heurístico que está originalmente ligado com 
as descobertas que o bebê faz, por exemplo, por meio do Cesto de Tesouros e após o primeiro ano de vida através dos jogos heurísticos. Já o brincar Telúrico preconiza a brincadeira livre das crianças, sua relação com a terra, com a natureza e os objetos naturais, dentro do espaço em habita.

Ao refletir sobre esses três eixos separadamente, ou seja, cultura, descobertas e natureza, cada qual ocupando seu status de importância para o ensino/aprendizagem na Educação Infantil é provável que a compreensão de tais conjecturas sejam consideradas e pensadas separadamente, mas o que se percebe é que estas formulações estão intimamente ligadas, como Piorski (2016, p. 20) apresenta:

São brinquedos da terra todas as representações ou mimeses da vida social. As brincadeiras de casinha e as de cabana, de fazendinha e de animais construídos, de boneca, de carroça, de carrinhos, incluindo os carros de boi, de madeira, de vara e de lata, de miniaturas, os brinquedos de modelar, as representações de casamento, nascimento, trabalho e beleza, os rituais de morte e os festejos religiosos, brinquedos e brincadeiras das entranhas de animais e plantas, feitos de ossos e seivas...

Segundo Blauth (2013) as crianças se fascinam com os elementos que encontram na natureza, ali compreendem ciclos, diversificados modelos e formas, distintas maneiras de sobrevivência, cheiros e sabores únicos. A fauna e a flora apresentam-se majestosas para novas descobertas, e o amor, o respeito, a consciência, a sensibilização pelo cuidado com a natureza devem ser proporcionados aos pequenos desde a Educação Infantil:

Andar na lama, tomar chuva, ouvir o pássaro, contemplar a flor acompanhar a borboleta, seguir as formigas carregadeiras, encontrar seres nas nuvens. [...] Enquanto o ser humano brinca, ele aprende, e aprende tão bem e tão gozozamente que nem parece aprendizado. (BLAUTH, 2013, p. 17 - 8).

Conforme Barros (2018) a escola necessita repensar sobre o "desemparedamento da infância" para a ressignificação das salas de aula, pátios, refeitórios, enfim toda a escola deve ser um espaço de contentamento e de alegria, privilegiando a autonomia, as novas descobertas e experimentação, caminhos pelos quais será possível o desenvolvimento de mais potencialidades infantis. "Todas as crianças, grandes e pequenas, têm o direito de viver experiências de contato direto com os elementos da natureza no ambiente escolar.” (p. 40).

De acordo com Brasil (2006) documento que ressalta a importância de diferenciadas estratégias para o ensino nas instituições de Educação Infantil, para o desenvolvimento 114

RELEDUC | ISE | v. 2 | n. 1 | fev. 2019 
progressivo da criança através de novos saberes, respeitando diversidades culturais e possibilitando situações de vivencias ao ar livre, tudo com o intuito de que desde pequenos, sejam instigados a observarem o mundo natural, as ações humanas e as inter-relações que os diferentes ecossistemas e espécies estabelecem para a sobrevivência e manutenção do grupo, dando-lhes a oportunidade para que usufruam da natureza e da cultura em que se inserem, por isso:

[...] atentamos para a necessidade de adoção de estratégias educacionais que permitam às crianças, desde bebês, usufruírem da natureza, observarem e sentirem o vento, brincarem com água e areia, atividades que se tornam especialmente relevantes se considerarmos que as crianças ficam em espaços internos às construções na maior parte do tempo em que se encontram nas instituições de Educação Infantil. (BRASIL, 2006, p. 17).

Neste sentido Brasil (2010) enfatiza que algumas práticas pedagógicas para as creches e pré-escolas, mas permite-lhes alternativas de um currículo flexível, tendo como principais eixos norteadores as interações e brincadeiras. Garantindo aos alunos experiências corporais, de diferentes linguagens e narrativas, de participação individual e coletiva, de autonomia, de vivencias éticas, estéticas e de identidade, interações com manifestações culturais e de uso de recursos tecnológicos. Conjuntamente com esses aspectos citados é perceptível que o brincar Heurístico e o brincar Telúrico são citados de forma implícita quando o documento coloca para as instituições que:

Incentivem a curiosidade, a exploração, o encantamento, o questionamento, a indagação e o conhecimento das crianças em relação ao mundo físico e social, ao tempo e à natureza; [...] Promovam a interação, o cuidado, a preservação e o conhecimento da biodiversidade e da sustentabilidade da vida na Terra, assim como o não desperdício dos recursos naturais. (BRASIL, 2010, p. 26).

Em conformidade com os conceitos da Teoria Histórico-Cultural, do brincar Heurístico e do brincar Telúrico, os instrumentos, ou seja, os objetos são imprescindíveis para o desenvolvimento da brincadeira, é por meio deles que a criança interpreta e se insere no mundo, descobre, ocupa-se e explora.

Os bebês, ao nascerem, ainda não possuem suas percepções desenvolvidas como é possível perceber nos adultos “[...] isto é, sua visão, audição e os demais órgãos de percepção - é quase não funcional num recém-nascido [...]”' (VYGOTSKY; LURIA, 1996, p. 155). Estes não conseguem identificar e reconhecer objetos que estão a sua volta, seu instinto seleciona 115

RELEDUC | ISE | v. 2 | n. 1 | fev. 2019 
coisas que lhes dão satisfação, por exemplo, a comida, visto que é pela boca que a criança pequena satisfaz sua maior necessidade, ou seja, alimentar-se.

Com o passar do tempo, quando chega a fase entre 2 e 4 anos de idade o mundo é percebido de forma primitiva, a criança quer tocar com suas mãozinhas, ter posse sobre as coisas, objetos e até mesmo sobre pessoas, percebe-se então que estes não dispõe de perspectiva visual de qualidade, assim "[...] a criança começa a conhecer o mundo primeiro com a boca, depois com as mãos; e só depois disso sua visão assenta as pedras angulares para percepções que se desenvolvem plenamente muito mais tarde". (VYGOTSKY; LURIA, 1996, p. 157-8). A partir desta concepção, percebe-se que a criança não tem ainda suas percepções visuais e auditivas bem desenvolvidas, por isso, obviamente irá compreender o mundo e as situações que as rodeiam cotidianamente de maneira diferente de como o adulto o faz.

Posteriormente, a criança começa a separar suas representações de acontecimentos reais, sendo capaz de representar, fantasiar e sonhar, se distanciando da realidade, porém é nesta fase que a criança permanece por um longo período de sua vida, ou seja, continua obtendo impressões externas as mistura com "imagens reais", guardadas em suas experiências passadas. Até que consiga, de fato, diferenciar sem confundir o concreto e o imaginário.

A fala e o pensamento da criança terão que desenvolver-se; sua experiência, com vistas à realidade, terá que se tornar firmemente estabelecida e adquirir suficiente independência; as nítidas imagens visuais "eidéticas", que tem papel tão importante na mente da criança, terão que desaparecer. Em suma, uma reconstrução cultural significativa terá que ter lugar para que a criança passe do estágio de percepções primitivas para o estágio seguinte - o estágio das formas competentes de adaptação ao mundo exterior. (VYGOTSKY; LURIA, 1996, p. 160, grifo do autor).

Conforme Machado (2016) é preciso criar oportunidades reais para que as crianças entrem em contato direto com a natureza, uma vez que sozinhas, dificilmente irão conseguir fazer tal conexão. O brincar ao ar livre, consiste também na observação de elementos que não são estáticos, pois estão mudando constantemente e requerem cuidados, por isso dialogam com as crianças, as fazem sentir a vitalidade e a harmonia para um desenvolvimento mais ativo da criatividade e imaginação, visto que as crianças pequenas:

[...] como os bebês, não falam e se manifestam por meio de outras linguagens expressivas, a saber: brincadeira, expressão musical, artística, corporal, gestual, entre outras. Outras expressões do "estado da arte" das crianças se manifestam em forma de doenças, atitudes, reações, temperamentos, todas 116

RELEDUC | ISE | v. 2 | n. 1 | fev. 2019 
elas "falas" absolutamente reveladoras simbólicas do universo infantil. (FRIEDMANN, 2015, p. 38, grifo do autor).

De acordo com Friedmann (2015) o que distingue as crianças, por exemplo, de jovens, adultos e idosos, é que elas estão em contínuo desenvolvimento, o que requer mais incitação aos seus órgãos dos sentidos, para assim - visão, audição, tato, olfato e paladar - tornarem-se mais apurados para atingir e completar os desafios posteriores a essa fase, aspectos muito importantes para um efetivo crescimento.

Na concepção de Mukhina (1995) as crianças imaginam conforme são disponibilizados a elas objetos e elementos que os fazem converter mentalmente sobre aquilo que desejam brincar, ou seja, começam a ter domínio sobre a representação de utilizar certo instrumento, mas com a função de outro. A posteriori, passam a resolver ocorrências e acontecimentos com suas experiências armazenadas anteriormente. Dessa forma é cabível a reflexão de que a criança ao desfrutar da oportunidade de brincar e jogar na fase pré-escolar terá mais facilidade em transferir para o papel, ao longo de sua trajetória escolar, em suas tarefas cotidianas, sua imaginação, por meio de desenhos, letras e/ou números.

\begin{abstract}
A imaginação da criança tem suas raízes na função semiótica da consciência, que surge no final da primeira infância [...] a imaginação da criança se desenvolve no jogo. Em uma primeira etapa, é inseparável das ações lúdicas. Quando a criança cavalga sobre um pau, nesse momento é um cavaleiro e o pau é um cavalo [...]. (MUKHINA, 1995, p. 290).
\end{abstract}

Para Blauth (2013) a criança ao observar um objeto, seja ele novo ou conhecido, tem a possibilidade de constatar e descobrir coisas novas, ou seja, outras utilidades e formas de manipular com mais familiaridade, pois “imaginação não é um dom, ela cresce e se desenvolve conforme a vazão de estímulos flui. Esse é um jogo infinito, de encantamento, de generosidade e beleza". (p. 92).

Segundo Piorski (2016) a cultura, a mídia e a sociedade são grandes influenciadoras do imaginar infantil, porém para o desenvolvimento da capacidade de criação da criança, sua imaginação requer novas descobertas e encantamentos, para assim, dialogar com seu interior, e para isso são necessários mais do que estímulos desconectados da realidade vívida, visto que “[...] imaginação é uma semântica, uma linguagem, e, como tal, requer um vocabulário de signos capazes de comunicar, de fazer sentido, de contatar seus significados.” (p. 60). 
Em sua obra Souza destaca (2007) sobre a Teoria Histórico-Cultural e a concepção de mediação explicitando que a relação entre sujeito e cultura não ocorre diretamente, ou seja, de maneira natural, mas são necessários instrumentos mediadores, que suplementam o vínculo do ser humano com o mundo, visto que "[...] o desenvolvimento cultural do homem presume sua interação constante com o meio natural, uma troca entre eles. Essa interação permite ao homem - sujeito de sua história - transformar a natureza”. (p. 73).

[...] Na sua forma mais elementar, o signo auxilia o homem nas tarefas que exigem memória e atenção. Os signos auxiliam o desempenho da atividade psíquica como elemento mediador entre o homem e seu entorno. Podemos dizer que os instrumentos de trabalho mediatizam originariamente a atividade humana, e os signos, como representação da realidade, mediatizam a atividade psíquica. Para Vigotski (1995), o signo pode ser produzido artificialmente pelo homem, constituindo um meio para domínio de seu comportamento. O instrumento pode ser caracterizado por um meio exterior e material, auxiliando o homem na resolução de tarefas. Este é dirigido a provocar modificações no objeto da atividade, ou seja, é o meio da atividade externa humana, destinado à conquista da natureza pelo homem, enquanto o signo dirige-se às mudanças internas no psiquismo humano. (SOUZA, 2007, p. 74).

Conforme Vygotsky e Luria (1996) para que ocorra a aprendizagem de habilidades humanas e a compreensão de seu papel no mundo social são necessários, instrumentos e signos. Os instrumentos irão ajudar as crianças a entenderem suas relações com o mundo exterior, são objetos e ferramentas que podem ser utilizados para satisfazer uma necessidade, são estes os mediadores, porém é um longo percurso e que acontece de forma processual durante o desenvolvimento humano, e que requer a mediação de outros mais experientes. Posteriormente a aquisição das formas de utilização de instrumentos, os signos são empregados como mediadores e estimulantes do comportamento, da memória e da atenção da criança.

De acordo com Moyles (2002) as pessoas que mantém relação direta com o cuidado e educação das crianças, assim como os professores, devem constantemente perguntar-se o porquê do brincar ser algo tão importante e satisfatório para os humanos e até para alguns animais. É preciso que cada um entenda e esclareça a significância desse termo e a sua relevância para o desenvolvimento efetivo dos processos de ensino/aprendizagem.

Para Blauth (2013) os pais ou responsáveis, e os professores devem fazer um resgate com as crianças, por exemplo, de brincadeiras antigas da infância, mas que as conecte com os adultos e com a natureza. Brincando junto, despertando a atenção, a curiosidade, o amor pela aprendizagem de maneira lúdica, respeitando o tempo e a personalidade de cada um, deixando-

$$
\text { RELEDUC | ISE | v. } 2 \text { | n. } 1 \text { | fev. } 2019
$$


lhes fazer escolhas sobre o que considera ser melhor enquanto brinca. Por isso "solte a criança no jardim, estimule-a, desperte-a com alguma brincadeira ou mostre para ela formas e cores, mas não dirija todas as suas atividades, deixe que ela descubra, permita que a imaginação dela possa emergir.” (p. 96).

Assim como os professores a escola também tem sua responsabilidade no que tange à educação da criança em contato com a natureza, para a busca de um ensino mais efetivo, real e concreto. A escola quando pensada e organizada para a educação e não apenas escolarização, deveria levar em consideração a incompletude de seus agentes primordiais, portanto educadores e educandos, e assim apoiá-los para redescobrir o ambiente escolar como que uma extensão de sua casa, sendo agradável e prazeroso estar ali. Dessa forma, a escola “[...] acolheria as curiosidades e as descobertas de seus alunos, ampliando as fronteiras de conhecimentos e experiências por meio de diálogos entre diversos territórios e sujeitos". (LEITE, 2015, p. 69).

Em vista dos argumentos apresentados, acredita-se que o professor deva saber, de fato, qual é a sua missão como educador de outras pessoas, das novas gerações, as quais dependem plenamente de seu bom exemplo, sua paciência, seu amor e de sua sabedoria para desenvolverem-se integralmente como cidadãos humanizados, que possam cuidar do planeta, de outras espécies e da própria raça humana.

O professor não pode apenas inculcar suas ideias e concepções em outros, mas deve ser o mediador, mostrando múltiplos caminhos e possibilidades com o intuito de que cada aluno, sendo um ser único e singular, possa fazer escolhas conscientes. Faz-se necessário a compreensão, a percepção e a reflexão de que o aluno não é só aluno, mas é uma vida humana que necessita de condições adequadas e de bons exemplos para se desenvolver e avançar no processo de ensino/aprendizagem a fim de alcançar o êxito de tornar-se um adulto responsável, feliz e crítico.

\section{CONSIDERAÇÕES FINAIS}

Neste sentido, defende-se aqui, que seja feita uma reflexão por parte dos professores, de como estão agindo em relação ao brincar, à criança e o seu contato com a natureza. O brincar não pode ser menosprezado pelos adultos, principalmente no ambiente escolar, em que inúmeras vezes as crianças são relegadas de aproveitarem os ambientes externos, passando 
horas sentadas, enfileiradas, em salas frias de concreto sem ao menos verem a luz do sol, com inúmeras tarefas e lições das quais não sentem prazer e/ou motivação em realizar.

Muitos professores ainda acreditam que ao levarem seus alunos ao pátio da escola para trabalharem certos conteúdos, a aula não atingirá os objetivos esperados. Outros afirmam que algumas crianças não se comportam quando estão fora da sala de aula, há ainda àqueles que não querem correr riscos, isto é, tem medo de que alguma criança se machuque durante a exploração dos ambientes.

Outra consideração que pode ser feita: é preciso informar e esclarecer para as crianças de que muitos dos recursos vitais, imprescindíveis e essenciais para a sobrevivência na Terra são finitos, como por exemplo, a água, alguns combustíveis e minérios, que com a má utilização podem vir a se extinguir. E que a manutenção de tais recursos naturais não renováveis irá depender da raça humana e de como ela se utiliza deles.

Os gestores, coordenadores, professores e demais agentes educacionais que atuam nas escolas, a sociedade, o poder público precisam compreender que as crianças necessitam mais do que conteúdos metodológicos abstratos. Sem a compreensão da importância de por que e para que aprender, não haverá, de fato, aprendizagem significativa, o que faz ressurgir o debate sobre a atual situação do sistema educacional, em que é "escola lá; vida de verdade cá. A vida verdadeira, na educação de massa, nos índices de aprendizado, só existe no futuro. Aprender abstrações para no futuro ser”. (PIORSKI, 2015, p. 85).

Nessas premissas, para a realização deste trabalho foram utilizadas a Teoria HistóricoCultural, os conceitos do brincar Heurístico e do brincar Telúrico, em que estes dois últimos correspondem, sucessivamente, ao brincar pelas descobertas e ao brincar com elementos da natureza, porém são brincadeiras mais espontâneas realizadas pela criança, mas a Teoria Histórico-Cultural aponta sobre a importância da mediação, por isso acredita-se que enquanto a criança brinca, desde muito pequena, se faz necessária à intervenção do professor nos espaços de ensino/aprendizagem. Conscientizando, sensibilizando e proporcionando-lhes momentos de reflexão sobre conceitos e acontecimentos que as circundam, em relação ao planeta, às outras espécies e a própria raça humana.

Assim, percebe-se que o mais importante não é dar para os pequenos brinquedos prontos, mas deixar que escolham as matérias, que toquem, apreciem, montem, desmontem e remontem, seguindo as imagens que tem em seu imaginar. $\mathrm{O}$ que tem valor para a criança é a construção, não o resultado final, sentir as texturas, os cheiros, o toque. A criança sente a 
necessidade de pertencer-se a brincadeira, e construir os brinquedos através da natureza representa para ela ser parte do brinquedo e também do mundo. Quanto mais simples for o brinquedo, mais imaginação ela terá de usar.

Dessa forma, é possível perceber que durante toda a vida acadêmica, as descobertas, conceito do brincar Heurístico e a natureza, conceito do brincar Telúrico, devem estar presentes, pois esse enfoque é transversal e precisa perpassar por todos os níveis de ensino, começando desde a Educação Infantil na creche e pré-escola, com o Cesto de Tesouros, os Jogos Heurísticos, o brincar livre com elementos da natureza.

Ninguém cuida do que não ama ou daquilo que não considera importante, por isso desde os primeiros anos de vida é extremamente importante sensibilizar e conscientizar os pequenos, proporcionando-lhes momentos de reflexões sobre o ambiente em que está inserido, sobre como as pessoas que as rodeiam estão agindo e cuidando em relação ao planeta, para possibilitar que as crianças entendam que o termo "jogar fora" é utilizado de forma errônea, visto que não há fora ou dentro, todos os espaços, até mesmo o dos lixões, fazem parte do planeta Terra.

Portanto, a criança não precisa de brinquedos caros, comprados em lojas e que representam aquilo que são na realidade, visto que para estes os fatos são entendidos de forma diferenciada. Aos adultos que permeiam o cotidiano da criança, seja no âmbito familiar e/ou escolar cabe à responsabilidade de disponibilizar ambientes e materiais que as crianças possam empregar sua imaginação, tendo a possibilidade de recriar e refazer a partir de componentes que as circundam, como por exemplo, os elementos que são advindos da natureza.

\section{REFERÊNCIAS}

BARROS, M. I. A. de (Org.) Desemparedamento da Infância: a escola como lugar de encontro com a natureza. Rio de Janeiro: Alana, 2018.

BLAUTH, G. Jardim das brincadeiras: uma estratégia lúdica para a educação ecológica. Edição do autor, 2013. Disponível em:<https://jardimdasbrincadeiras.files.wordpre ss.com/2013/09/jardim-das-brincadeiras.pdf>. Acesso em: 28 jun. 2018.

BRASIL. Ministério da Educação. Secretaria de Educação Básica. Diretrizes Curriculares Nacionais para a educação infantil / Secretaria da Educação Básica. - Brasília: MEC, SEB, 2010. Disponível em:<http://ndi.ufsc.br/files/2012/02/Diretrizes-Curriculares-para-a-E-I.pdf>. Acesso em: 03 maio. 2018.

Secretaria do Ensino Fundamental. Parâmetros Nacionais de Qualidade para a Educação Infantil - Volume 1. Brasília: 2006.

$$
\text { RELEDUC | ISE | v. } 2 \text { | n. } 1 \text { | fev. } 2019
$$


Lei das Diretrizes e Bases da Educação Nacional. Lei n 9394/96 de 20 de dezembro de 1996. Estabelece as diretrizes e bases da Educação Nacional. Diário Oficial da U nião, Brasília. D.F. Disponível em: <https://www.planalto.gov.br/ccivil_03/Leis/L9394.htm>. Acesso em: 09 maio. 2018.

(1990). Estatuto da Criança e do Adolescente. 8069. Disponível em: <http://www. conselhodacrianca.al.gov.br/sala-de-imprensa/publicacoes/ECA\%20ATUALIZADO.pdf/ view>. Acesso em: 28 abr. 2018.

\section{Constituição (1988). Constituição da República Federativa do Brasil:}

Senado Federal, 1988. Disponível em:<http://www.stf.jus.br/arquivo/cms/legislacaoConstitui cao/anexo/CF.pdf>. Acesso em: 20 mar. 2018.

CRAEMER, U. O brincar na comunidade: uma comunidade se transforma com a arte lúdica. In: MEIRELLES, R. (Org.) Território do brincar: diálogo com escolas. São Paulo: Instituto Alana, 2015. p. 47-50.

ELKONIN, D. B. Psicologia do jogo. Tradução Álvaro Cabral. - São Paulo: Martins Fontes, 1998.

FRIEDMANN, A. O olhar antropológico por dentro da infância: adentrando nas casinhas das crianças. In: MEIRELLES, R. (Org.) Território do brincar: diálogo com escolas. São Paulo: Instituto Alana, 2015. p. 36 - 45.

GOLDSCHMIED, E.; JACKSON, S. Educação de 0 a 3 anos: $\mathrm{O}$ atendimento em creche. Tradução Marlon Xavier. 2. ed. Porto Alegre: Artmed, 2006.

LEITE, A. C. A. Diálogos e Experiências: pontes que conectam pessoas e territórios. In: MEIRELLES, R. (Org.) Território do brincar: diálogo com escolas. São Paulo: Instituto Alana, 2015. p. 61-70.

MACHADO, A. L. Brincando com os 4 elementos da natureza. s.1.: s.e., 2016. Disponível em: <http://www.educandotudomuda.com.br/ebook/>. Acesso em: 21 maio. 2018.

MAJEM, T. A cesta dos tesouros. In: MAJEM, T; ÒDENA, P. Descobrir brincando. Tradução Suely Amaral Mello e Maria Carem Silveira Barbosa; revisão técnica Ana Lúcia Goulart de Faria. Campinas: Autores Associados, 2010.

Cotidiano escolar e infância: interfaces da educação infantil e do ensino fundament al nas vezes de seus protagonistas. Tese (Doutorado em Educação Escolar) Universidade Esta dual Paulista, Faculdade de Ciências e Letras, Campus de Araraquara. São Paulo, 2012.

Disponível em: <http://wwws.fclar.unesp.br/agenda-pos/educacao_escolar/2555.pdf >. Acesso em: 13 maio. 2018.

MEIRELLES, D. da S. Brincar heurístico: a brincadeira livre e espontânea das crianças de 0 a 3 anos de idade. Universidade Federal do Rio Grande do Sul. Faculdade de Educação.

Especialização em Docência na Educação Infantil. Porto Alegre, 2016.

$$
\text { RELEDUC | ISE | v. } 2 \text { | n. } 1 \text { | fev. } 2019
$$


MOREIRA, A. A. A. Brincar: um direito da infância uma responsabilidade da escola. In: ANGOTTI, M. (Org.). Educação infantil: para que, para quem e por quê? Campinas: Alínea, 2006.

MOYLES, J. R. Só brincar? O papel do Brincar na educação infantil. Porto Alegre: Artmed, 2002.

MUKHINA, V. Psicologia da idade pré-escolar. Tradução Claudia Berliner. São Paulo: Martins Fontes, 1995.

PIORSKI, G. Brinquedos do chão: a natureza, o imaginário e o brincar. São Paulo: Peirópolis, 2016.

SOUZA, M. C. B. R. A concepção de criança para o Enfoque Histórico Cultural. Tese (D outorado em Educação) - Faculdade de Filosofia e Ciências, Universidade Estadual Paulista, 2007. Disponível em: <https://www.marilia.unesp.br/Home/Pos-Graduacao/Educacao/Disse rtacoes/souza_mcbr_dr_mar.pdf >. Acesso em: 03 maio. 2018.

VYGOTSKY, L. S.; LURIA, A. R. Estudo sobre a história do comportamento: símios, homem primitivo e criança. Tradução Lólio Lourenço de Oliveira. Porto Alegre: Artes Médicas, 1996. 